\title{
BMJ Open COVID-19 symptom surveillance in immunocompromised children and young people in the UK: a prospective observational cohort study
}

Meera Shaunak, ${ }^{1}$ Ravin Patel (D) , ${ }^{2}$ Corine Driessens, ${ }^{2,3}$ Lynne Mills, ${ }^{1}$ Alice Leahy, ${ }^{4}$ Diane Gbesemete, ${ }^{1,2}$ Daniel R Owens, ${ }^{1,2}$ Jane S Lucas, ${ }^{2,3,5}$ Saul N Faust (1) ,1,2,5 Hans de Graaf, ${ }^{1,2,4}$ On behalf of the ImmunoCOVID19 study group

To cite: Shaunak M, Patel R, Driessens C, et al. COVID-19 symptom surveillance in immunocompromised children and young people in the UK: a prospective observational cohort study. BMJ Open 2021;11:e044899. doi:10.1136/ bmjopen-2020-044899

- Prepublication history and additional materials for this paper is available online. To view these files, please visit the journal online (http://dx.doi. org/10.1136/bmjopen-2020044899).

MS and RP contributed equally. SNF and HdG contributed equally.

Received 22 September 2020 Revised 23 December 2020 Accepted 18 February 2021
Check for updates

(c) Author(s) (or their employer(s)) 2021. Re-use permitted under CC BY-NC. No commercial re-use. See rights and permissions. Published by BMJ.

For numbered affiliations see end of article.

Correspondence to

Dr Hans de Graaf;

h.de-graaf@soton.ac.uk

\section{ABSTRACT}

Objectives To describe the frequency of symptoms compatible with SARS-CoV-2 infection in immunocompromised children and young people in the UK during the SARS-CoV-2 pandemic. To describe patient/ parent anxiety regarding SARS-CoV-2 infection in this cohort.

Design A prospective observational cohort study. Setting 46 centres across the UK between 16 March and 4 July 2020. A weekly online questionnaire based on the International Severe Acute Respiratory and emerging Infections Consortium-WHO Case Report Form was used to collect participant reported data on symptoms, test results, National Health Service attendance, hospital admission and impact on daily life.

Participants 1490 immunocompromised children, defined as those requiring an annual influenza vaccination due to their underlying condition or medication.

Main outcome measures Incidence of SARS-CoV-2-like symptoms and patient/parent anxiety score.

Results Over 16 weeks during the first wave of the pandemic, no SARS-CoV-2 infection was diagnosed in this large immunocompromised paediatric cohort (median age 11 years, 54.4\% female). 110 symptomatic participants underwent a test for SARS-CoV-2; all were negative. 922 (67.4\%) participants reported at least one symptom consistent with suspected SARS-CoV-2 infection over the study period. 476 (34.8\%) reported three or more symptoms. The most frequently reported symptoms included joint pain, fatigue, headache, nausea and muscle pain. SARS-CoV-2 testing during this period was performed on admitted patients only. 137 participants had their medication suspended or changed during the study period due to assumed COVID-19 disease risk. $62 \%$ reported high levels of anxiety (scores of 7-10 out of 10) at the start of the study, with anxiety levels remaining high throughout the study period.

Conclusions Although symptoms related to SARS-CoV-2 infection in children were common, there were no positive tests in this large immunocompromised cohort. Symptombased screening to facilitate early detection of SARSCoV-2 infection may not be helpful in these individuals. Patient/parent anxiety about SARS-CoV-2 infection was high.

Trial registration number NCT04382508.
Strengths and limitations of this study

- Large prospective cohort of immunocompromised children.

- High response rate of patients to questionnaire.

- Patient reported data.

- Limited SARS-CoV-2 testing due to shortage in national supply.

\section{INTRODUCTION}

COVID-19 is an ongoing global health crisis with over 11500000 cases and in excess of 500000 deaths worldwide. The illness is caused by SARS-CoV-2. As of 5 August 2020, the WHO reported 306297 cumulative cases of confirmed SARS-CoV-2 infection in the UK population of 68.1 million, giving a cumulative incidence of $0.004 \%{ }^{1}$

SARS-CoV-2 causes mild or moderate upper respiratory tract infection in the majority of children, with fever and cough being the most common symptoms, although many are asymptomatic. ${ }^{2}$ In children, fewer cases of SARS-CoV-2 infection have been reported compared with adults. ${ }^{3}$ However, it remains unclear how many children in the community have been infected, with the results of seroprevalence studies awaited. ${ }^{4}$

Data demonstrating an increased risk of severe disease in immunocompromised adults are emerging (A Richter, personal communication 2020, publication submitted). Children with significant comorbidities are also currently considered to be at higher risk of severe infection. They were given specific precautionary advice when UK lockdown was applied, to slow the spread of SARS-CoV-2, on 23 March 2020. ${ }^{56}$

The primary objective of this study is to describe the frequency of symptoms compatible with SARS-CoV-2 infection in 
immunocompromised children and young people, a subset of the population in whom there is limited reported data. A secondary objective of this study is to describe patient/parent anxiety regarding SARS-CoV-2 infection.

\section{METHODS}

In this prospective cohort study, immunocompromised patients under 18 years were identified by the clinical teams at 46 hospitals across the UK (online supplemental appendix B). Children and young people were considered to be immunocompromised if they required an annual influenza vaccination due to their underlying condition or medication, following the immunisation against infectious disease UK government guidance. ${ }^{7}$

\section{Patient and public involvement (PPI)}

Study design included PPI. Parents of children on immunosuppressive drugs were asked about their willingness to participate in such a study and whether they had any specific questions or anxieties.

Parents and participants were sent age-appropriate patient information sheets and asked to complete an online consent form. If they did not reply after receiving electronic reminders in the following 3 weeks, they were removed from the study database. Following completion of online consent, participants were sent a weekly online questionnaire based on the International Severe Acute Respiratory and emerging Infections Consortium and WHO COVID-19 Case Report Form, ${ }^{8}$ with questions also incorporating PPI feedback (online supplemental appendix C: weekly questionnaire). Depending on the age and ability of the child or young person, questionnaires were either completed by the participant or their parent or carer.

From 16 March 2020, information was collected regarding symptom presentation, test results, National Health Service (NHS) attendance, hospital admission and the effects of COVID-19 on daily life. Loss of smell or taste was added to the weekly questionnaire at week 14 following emerging evidence for anosmia and ageusia in COVID-19 disease. Study participants were advised that the study did not replace normal healthcare provision and were asked to follow government guidance and seek medical advice via emergency healthcare providers or the child's normal clinical team if concerns about symptoms arose. The study team did not provide advice on SARS-CoV-2 testing. During the study period, in the UK testing was limited to patients possibly needing admission (due to national testing capacity).

Study recruitment closed on 4 July 2020. Data collection is ongoing, and follow-up is planned to continue for 12 months.

\section{Statistical analysis}

Longitudinal data were collected as participants were asked to complete a weekly online questionnaire for 1 year. We report data up to the 4 July 2020, when lockdown restrictions in the UK were eased. All questionnaire data collected over this 16-week study period were included in the analysis, although some participants did not complete the questionnaire every week. Participants who did not complete any questionnaires were not included in the analysis. Analysis assumed that the date of entry into the study was the date of the first completed questionnaire. Data were cleaned and analysed every week, and a toplevel report was provided to NHS England and the Royal College of Paediatrics and Child Health. The descriptive statistics presented in this paper were analysed using SAS V.9.4. Spearman correlation was used to analyse the correlation between anxiety scores and number of symptoms.

\section{RESULTS}

Recruitment increased over the 16-week study period (figure 1). By week 16, 1490 eligible patients or their parents had consented. Weekly online questionnaire response rate varied between $74 \%$ and $100 \%$ (figure 1). The median age of participants was 11 years (range 0-18 years), $54.5 \%$ of participants were female. Baseline

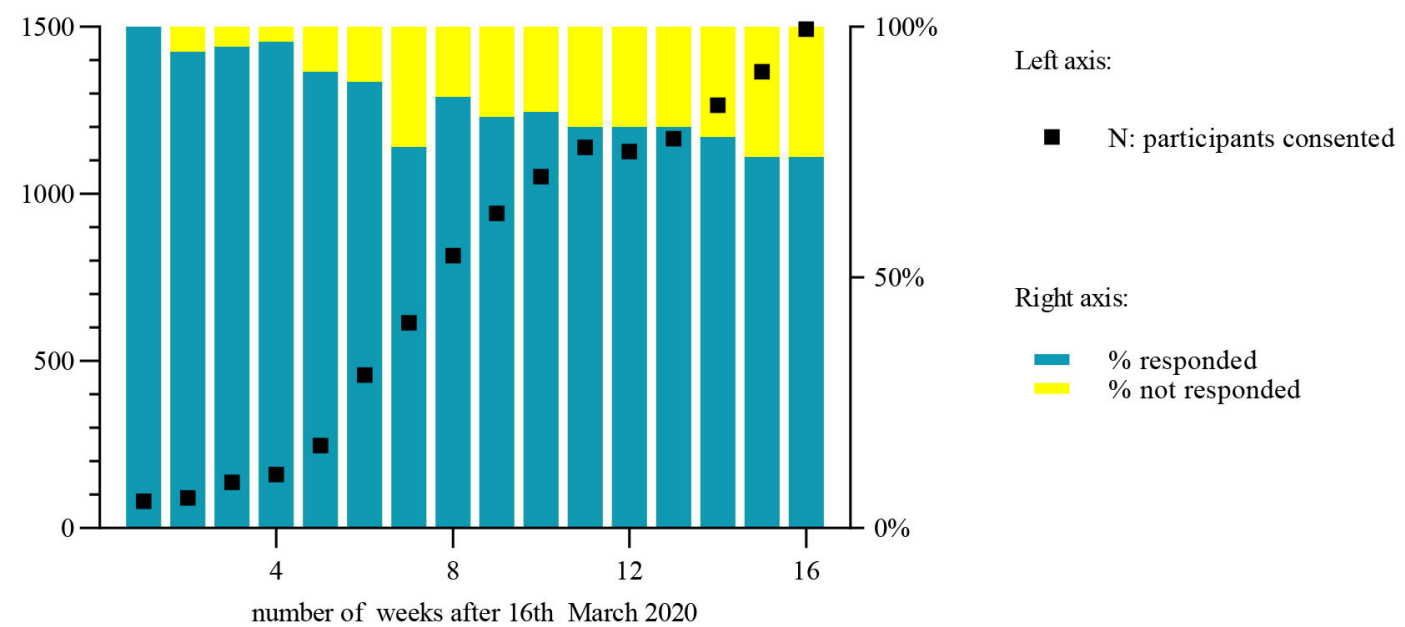

Figure 1 Study recruitment and weekly questionnaire response rate. 
Table 1 Baseline characteristics: primary diagnosis and medication

\begin{tabular}{|c|c|c|c|}
\hline & Male & Female & Total \\
\hline & $\mathbf{N}(\%)$ & $\mathbf{N}(\%)$ & $\mathbf{N}(\%)$ \\
\hline \multicolumn{4}{|l|}{ Primary diagnosis } \\
\hline Juvenile idiopathic arthritis & $140(20.6)$ & $314(38.7)$ & $454(30.5)$ \\
\hline Other rheumatological diagnoses & $48(7.1)$ & $110(13.6)$ & $158(10.6)$ \\
\hline Immunodeficiency disorders & $64(9.4)$ & $53(6.5)$ & $117(7.9)$ \\
\hline Solid organ or bone marrow transplant & $53(7.8)$ & $36(4.4)$ & $89(6.0)$ \\
\hline Renal disease & $56(8.2)$ & $27(3.3)$ & $83(5.6)$ \\
\hline Malignant haematology and oncological diagnoses & $51(7.5)$ & $28(3.5)$ & $79(5.3)$ \\
\hline Airways disease & $29(4.3)$ & $24(3.0)$ & $53(3.6)$ \\
\hline Inflammatory bowel disease & $29(4.3)$ & $23(2.8)$ & $52(3.5)$ \\
\hline Diabetes & $30(4.4)$ & $19(2.3)$ & $49(3.3)$ \\
\hline Neurological diagnoses & $20(2.9)$ & $10(1.2)$ & $30(2.0)$ \\
\hline Other gastroenterology and hepatology diagnoses & $7(1.0)$ & $12(1.5)$ & $19(1.3)$ \\
\hline Other & $26(3.8)$ & $34(4.2)$ & $60(4.0)$ \\
\hline Missing diagnosis & $126(18.6)$ & $121(14.9)$ & $247(16.6)$ \\
\hline Total & $679(45.6)$ & $811(54.4)$ & $1490(100)$ \\
\hline \multicolumn{4}{|l|}{ Medication } \\
\hline Methotrexate & $137(20.2)$ & $249(30.7)$ & $386(25.9)$ \\
\hline Anti-Tumor Necrosis Factor therapy & $101(14.9)$ & $202(24.9)$ & $303(20.3)$ \\
\hline Corticosteroids & $134(19.7)$ & $115(14.2)$ & $249(16.7)$ \\
\hline Other antibiotics and antivirals & $105(15.5)$ & $63(7.8)$ & $168(11.3)$ \\
\hline Calcineurin inhibitors & $87(12.8)$ & $71(8.8)$ & $158(10.6)$ \\
\hline Mycophenolate mofetil & $64(9.4)$ & $67(8.3)$ & $131(8.8)$ \\
\hline Other disease-modifying antirheumatic drugs & $56(8.2)$ & $53(6.5)$ & $109(7.3)$ \\
\hline Inhalers & $46(6.8)$ & $40(4.9)$ & $86(5.8)$ \\
\hline Insulin & $46(6.8)$ & $36(4.4)$ & $82(5.5)$ \\
\hline Non-steroidal anti-inflammatory drugs & $21(3.1)$ & $51(6.3)$ & $72(4.8)$ \\
\hline Chemotherapy & $41(6.0)$ & $27(3.3)$ & $68(4.6)$ \\
\hline Azithromycin & $40(5.9)$ & $28(3.5)$ & $68(4.6)$ \\
\hline Hydroxychloroquine & $11(1.6)$ & $44(5.4)$ & $55(3.7)$ \\
\hline Tocilizumab & $16(2.4)$ & $33(4.1)$ & $49(3.3)$ \\
\hline Intravenous or subcutaneous immunoglobulin & $21(3.1)$ & $17(2.1)$ & $38(2.6)$ \\
\hline Other biological drugs & $14(2.1)$ & $22(2.7)$ & $36(2.4)$ \\
\hline
\end{tabular}

characteristics of participants are shown in table 1 . When participants had more than one diagnosis, the primary diagnosis is reported.

Information regarding primary diagnosis was incomplete for $247(16.6 \%)$ participants. Of 1368 participants who completed at least 1 weekly online questionnaire, 922 $(67.4 \%)$ reported at least one symptom consistent with suspected SARS-CoV-2 infection over the study period. Four hundred and seventy-six $(34.8 \%)$ reported three or more simultaneous symptoms. The most frequently reported symptoms included joint pain, fatigue, headache, nausea and muscle pain. Symptoms according to primary diagnosis and medication can be found in online supplemental appendix D.
Figure 2A depicts the relationship between cough, fever, sore throat and shortness of breath, with some degree of overlap between these symptoms. The frequency of cough, blocked nose and sore throat decreased in both airways and non-airways disease participants over the study period (figure $2 \mathrm{~B}$ and $\mathrm{C}$ ). This trend was more marked in those with airways disease (figure 2B).

Fifty-three participants $(3.9 \%)$ visited primary or secondary NHS care due to concerns about SARS-CoV-2 infection, of whom $47(88.7 \%)$ reported symptoms. Two participants were admitted to hospital. One hundred and thirty-five participants $(9.9 \%)$ underwent a viral PCR test for SARS-CoV-2 infection. One hundred and ten of these reported symptoms. None of the study participants tested 


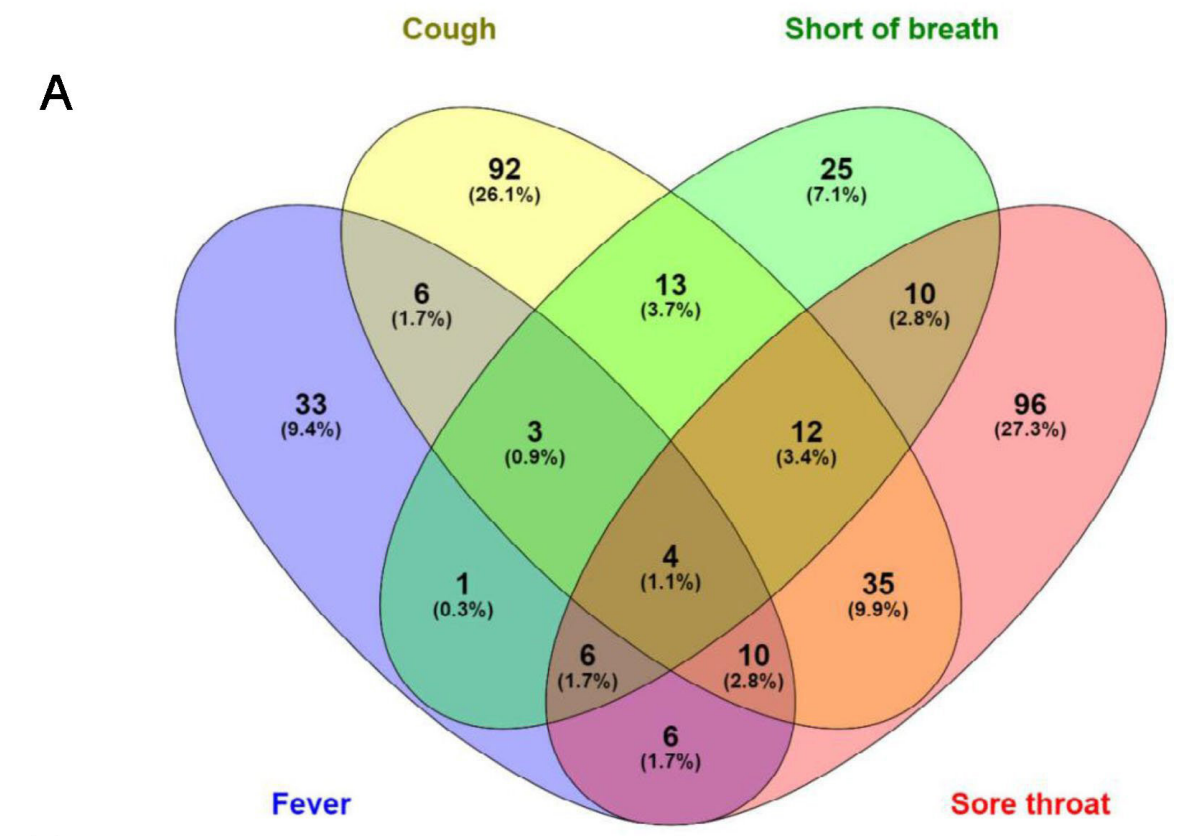

B

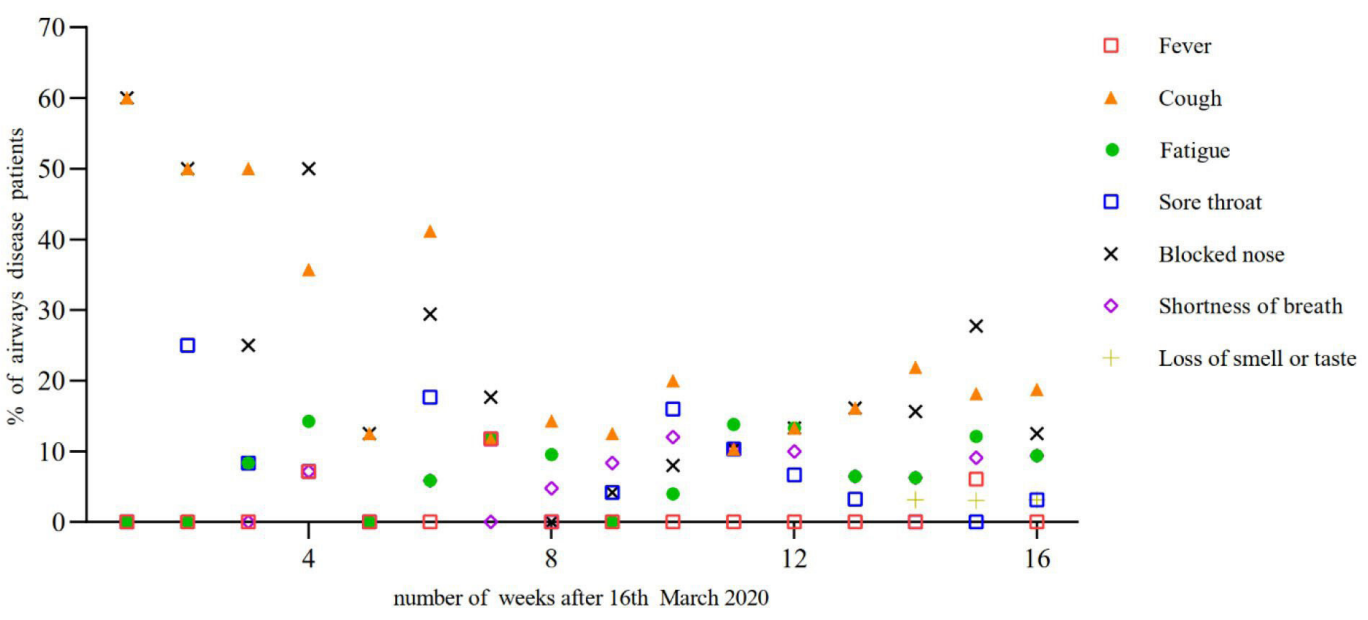

\section{C}

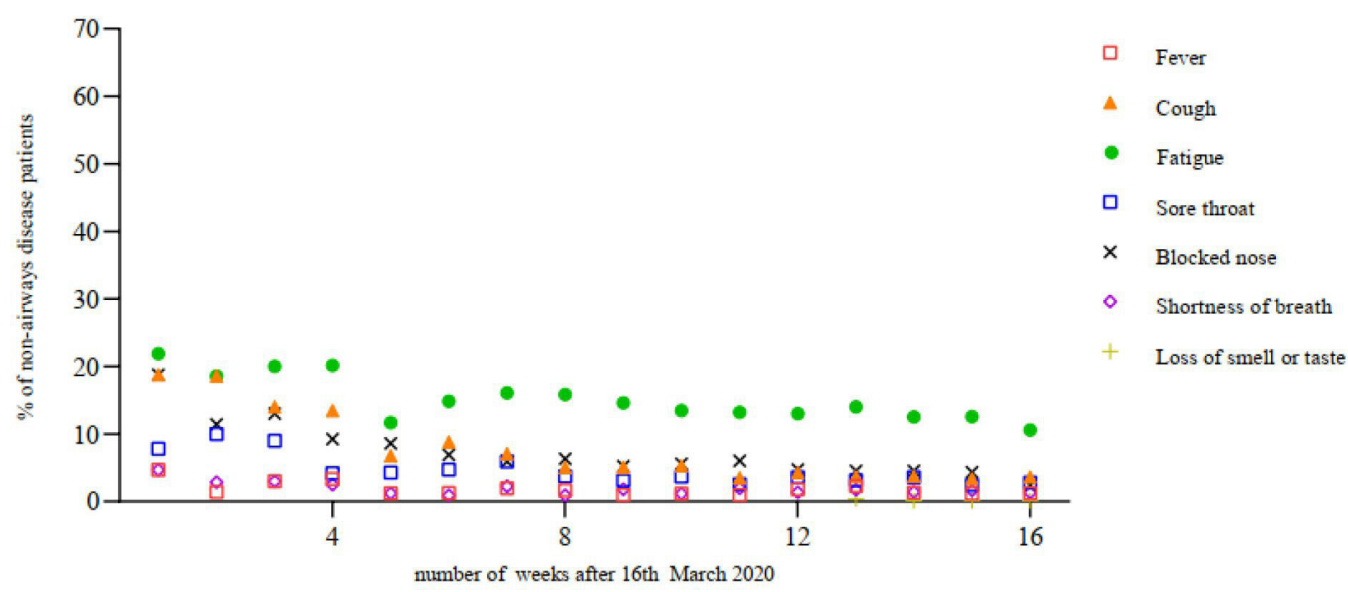

Figure 2 (A) Venn diagram depicting the association between fever, cough, shortness of breath and sore throat during the study period. (B) Reported symptoms in airways disease patients over time. (C) Reported symptoms in non-airways disease patients over time. 
positive for SARS-CoV-2 infection. One hundred and thirty-seven participants had their medication suspended or changed during the study period due to assumed risk of SARS-CoV-2 disease. Of these 117 (85.4\%) reported symptoms.

Figure 3A illustrates relatively static low school attendance over the 16-week study period, during which schools were closed to the majority of children. Sixty-two per cent of questionnaire respondents reported high levels of anxiety (scores of 7-10 out of 10) at the start of the study, with anxiety levels remaining extremely high throughout (figure 3B). With the easing of lockdown restrictions in July 2020, anxiety themes included concerns regarding the severity of SARS-CoV-2 infection, the reopening of schools and a second wave of infection. The correlation between number of symptoms and anxiety was not significant using cross-sectional Spearman correlation.

\section{DISCUSSION}

While $922(67.4 \%)$ participants reported one or more symptoms consistent with suspected SARS-CoV-2 infection, of the 110 who underwent viral PCR testing, none tested positive for SARS-CoV-2, suggesting an absence of symptom specificity. ${ }^{2}$

Symptoms of SARS-CoV-2 infection overlap with those of chronic disease exacerbations and medication side effects. Joint pain was frequently reported, reflecting the contribution of rheumatological diagnoses to the cohort. This suggests symptom-based screening for SARS-CoV-2 infection may not be helpful in these immunocompromised children and young people.

We are unable to comment on the incidence rate of SARS-CoV-2 infection in this cohort without comprehensive serological data. However, we can assume that only mild cases of SARS-CoV-2 infection were missed, as none of these 'high risk' patients had severe enough SARS-CoV-2 infection to require hospital admission. This study period encompassed the peak in confirmed SARS-CoV-2 cases in the UK, during which time many immunocompromised children were shielding. Either shielding measures were effective, or like healthy children, immunocompromised children are less affected by SARS-CoV-2 infection than adults. $^{910}$

In the UK, of the 651 children with laboratory confirmed SARS-CoV-2, between 17 January and 3 July 2020, only 48 $(8 \%)$ had a haematological, oncological or immunological comorbidity. ${ }^{11}$ There was no significant difference in the presenting symptoms of the immunocompromised compared with the rest of the paediatric cohort (O Swann, personal communication 2020). Limited data for paediatric oncology, liver transplant, chronic kidney disease and inflammatory bowel disease patients are reassuring, with few cases of mostly mild infection reported. ${ }^{12-16}$ While some studies show adult patients on immunosuppressive biologicals may not be at higher risk of severe disease, ${ }^{17}$ other analyses suggest that adults with malignancy, autoimmune conditions, asplenia and other immunosuppressive conditions are at greater risk of COVID-19 related death. ${ }^{18}$ However, the contribution of immunosuppression to SARS-CoV-2 disease severity in children remains unclear due to the low prevalence of severe disease in this age group. ${ }^{19}$

The frequency of cough, blocked nose and sore throat decreased in both airways and non-airways disease participants over the study period. This may suggest that shielding measures may have been effective in reducing the transmission of respiratory viruses in these children, similar to other studies. ${ }^{20}$ However, this observation is unsupported by serological data.

Fifty-three participants sought NHS attention, and only two were admitted to hospital, in keeping with reports that the proportion of vulnerable paediatric inpatients has significantly decreased during the pandemic. ${ }^{21}$ This implies that either families were successfully managing minor or chronic symptoms at home, or they were not accessing healthcare appropriately. A decrease in attendances to paediatric emergency departments has been reported in the UK following the start of the pandemic. ${ }^{22}$ While concerns were initially raised about delayed presentations of serious illness, ${ }^{23}$ a formal survey found this to be rare. ${ }^{24}$ It may also be possible that the reduction in 'normal' upper and lower respiratory infection transmission prevented by self-isolation and increased hand hygiene during the lockdown period has had the indirect effect of also reducing other reported minor or chronic symptoms in this cohort.

More than $50 \%$ of questionnaire respondents reported high levels of anxiety at the start of the study, similar to national figures. ${ }^{25}$ However, anxiety scores remained extremely high during this study, whereas average anxiety scores nationally reduced from 5.2 to 4.0 out of 10 by May $2020 .{ }^{25}$ With the advice to stop shielding from 31 July 2020, the planned reopening of schools in September 2020 and uncertainty regarding a second wave of infection, these families require up-to-date, evidencebased guidance on the need for specific precautionary measures. If such evidence is not available, a holistic, child-centred approach must be taken by clinicians on a case-by-case basis. ${ }^{6}$

Study limitations include patient or parent reported information, unverified by clinical review. Inconsistent completion of weekly questionnaires over the study period may have affected the data, although a median response rate of $83 \%$ (range $74 \%-100 \%$ ) is high for a questionnaire study. Over-reporting of symptoms may have occurred particularly as anxiety levels were high. Under-reporting of symptoms may also have occurred due to the nature of the study, which required weekly participation. Only 110 out of 922 participants with symptoms underwent viral PCR testing; therefore, some cases of mild SARS-CoV-2 infection may have been missed.

During the initial weeks of the outbreak, viral PCR tests were only performed if a child was admitted to hospital. Although all subspecialties in each hospital were approached to take part in the study, not all decided to 


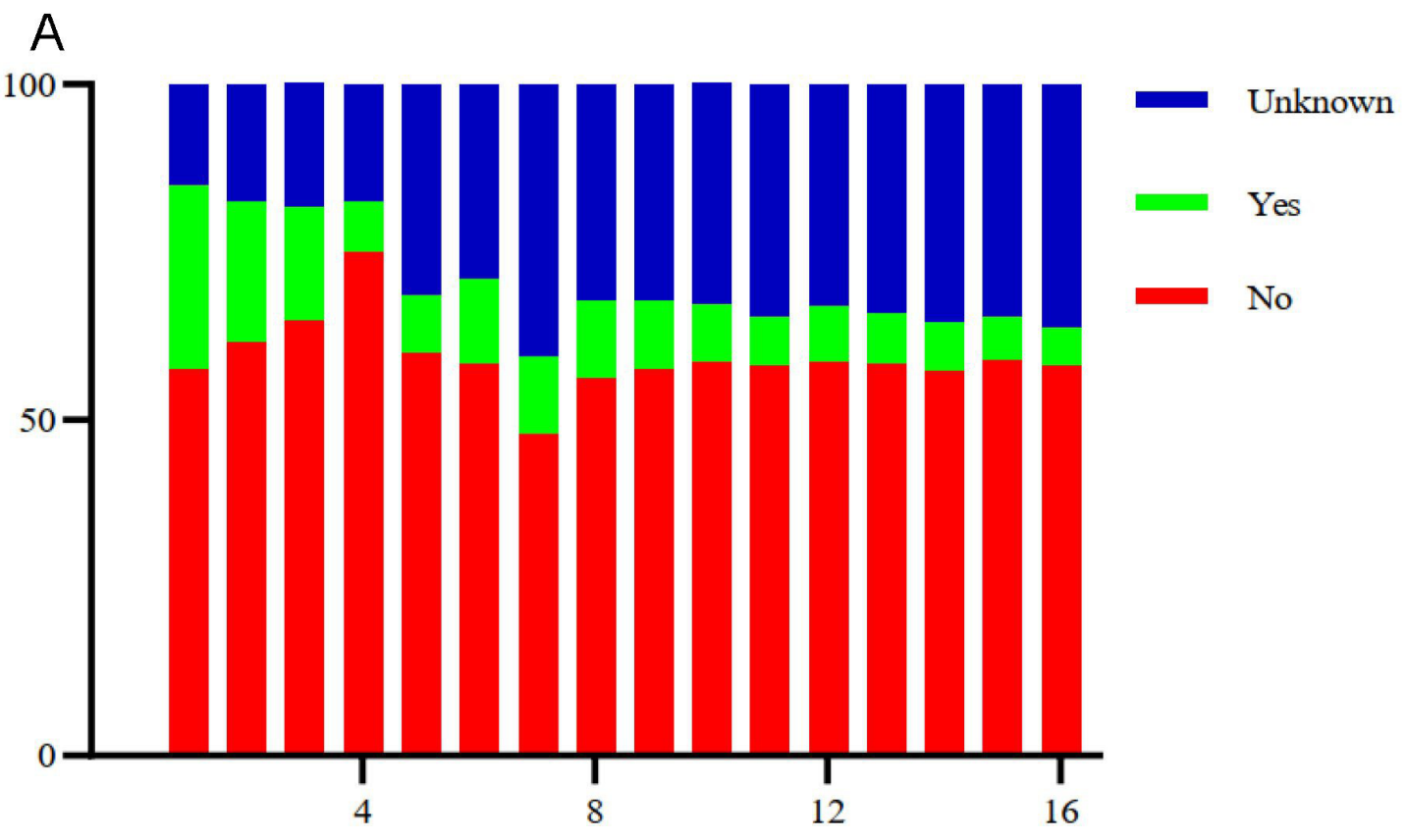

number of weeks after 16th March 2020

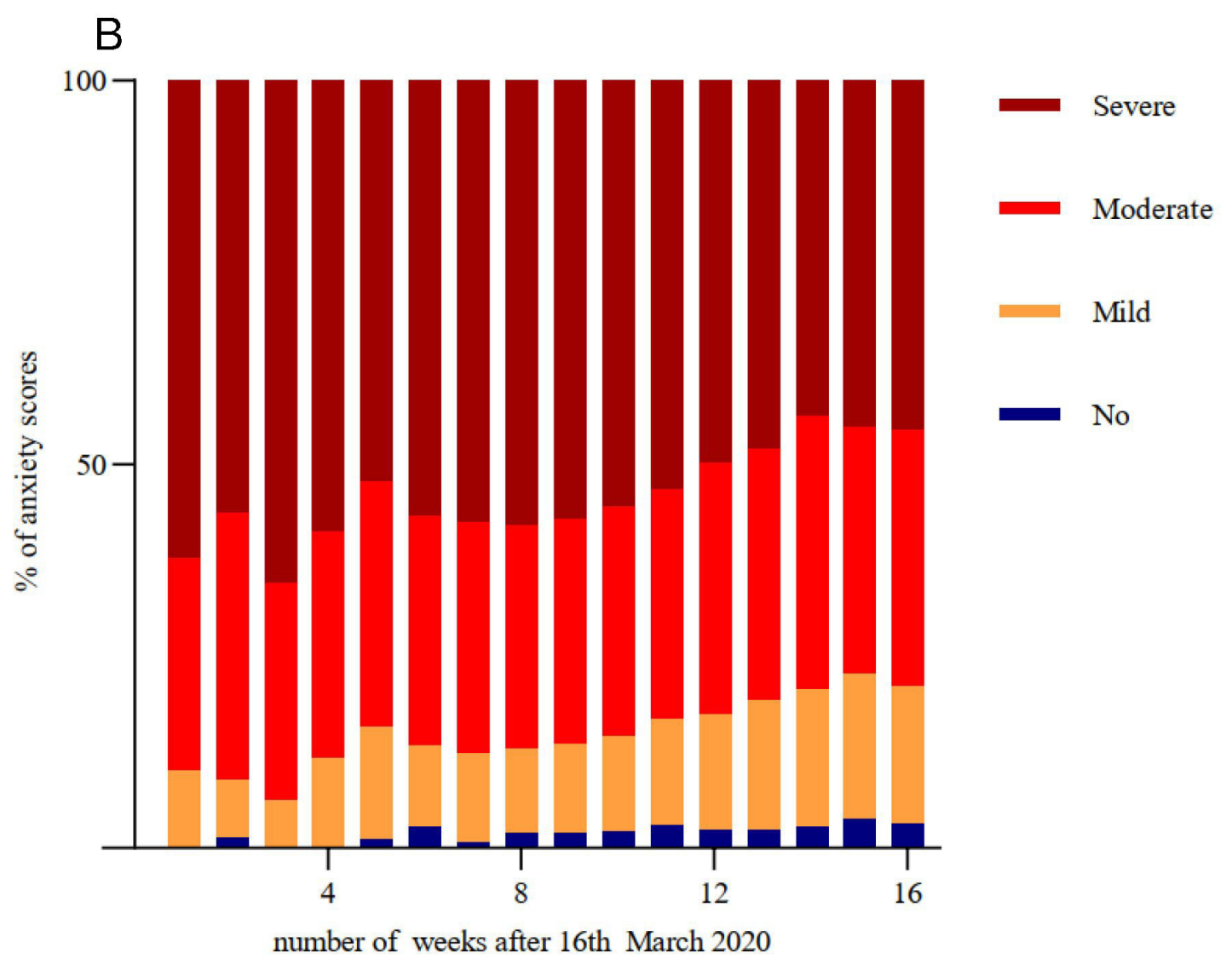

Figure 3 (A) Reported school attendance over time. (B) Reported anxiety levels over time. Anxiety scores out of 10 categorised into mild (1-3), moderate (4-6) and severe (7-10) anxiety, with a score of 0 indicating no anxiety. 
participate. This may have caused bias in the composition of the cohort.

Information on SARS-CoV-2 prevalence, progression and outcomes in children is still limited, with the results of national surveillance programmes awaited. Whether children with pre-existing comorbidities are more likely to contract SARS-CoV-2 infection remains unclear. Further research is warranted to identify risk factors for severe infection in children and young people to aid health service planning, improve public health messaging and minimise unforeseen consequences of imposed restrictions on child health and well-being.

In conclusion, this is the first study to prospectively observe a cohort of immunocompromised paediatric patients during the COVID-19 pandemic. We report results from a large cohort of 1490 patients over 16 weeks. Although symptoms indicative of SARS-CoV-2 infection were common in this cohort of immunocompromised children and young people, none of these 'high risk' patients had severe SARS-CoV-2 infection requiring hospital admission. While this observation is reassuring, clinicians need to remain cautious when counselling families as symptom-based screening to facilitate the early detection of SARS-CoV-2 infection may not be helpful. In addition, these patients/parents remain very anxious, highlighting the pressing need to clearly define and communicate SARS-CoV-2 risk in children and young people.

\section{Author affiliations}

${ }^{1}$ NIHR Southampton Clinical Research Facility, University Hospital Southampton NHS Foundation Trust, Southampton, UK

${ }^{2}$ Faculty of Medicine and Institute for Life Sciences, University of Southampton, Southampton, UK

${ }^{3}$ PCD Centre, University Hospital Southampton NHS Foundation Trust, Southampton, UK

${ }^{4}$ Paediatric Rheumatology, University Hospital Southampton NHS Foundation Trust, Southampton, UK

${ }^{5} \mathrm{NIHR}$ Southampton Biomedical Research Centre, University Hospital Southampton NHS Foundation Trust, Southampton, UK

Acknowledgements We would like to acknowledge all the children, young people and parents participating in this study. This study was badged as a UK National Institute for Health Research (NIHR) Urgent Public Health Study, and we would also like to thank the NIHR Clinical Research Network (CRN) and all associated NIHR Local CRNs and site staff who supported recruitment.

Collaborators The ImmunoCOVID19 study group (a full list of coauthors is provided in Supplementary Online Appendix A).

Contributors RP, HdG and SF planned the study. RP, MS and HdG managed the study and contributed to all parts of the manuscript. LM managed the patient data. CD provided statistical analysis. AL, DG, DO, JSL and SF contributed to managing the study and the writing, reviewing and editing of the manuscript. All members of the ImmunoCOVID group assisted with patient recruitment.

Funding The study was funded by the British Paediatric Allergy Immunity and Infection Group (BPAllG) and SNF's NIHR Senior Investigator Award. SNF, MS and DO are funded in part by the NIHR Southampton Clinical Research Facility. CD and JL are funded by NHS England for Highly Specialised Services (Primary Ciliary Dyskinesia Centre, University Hospital Southampton NHS Foundation Trust). Additional project management and information technology support was provided by the staff and resources of the NIHR Southampton Clinical Research Facility.

Competing interests All authors have completed the ICMJE uniform disclosure form at www.icmje.org/coi_disclosure.pdf. HdG received grant funding from the
BPAllG for the submitted work; there are no other relationships or activities that could appear to have influenced the submitted work.

Patient consent for publication Not required.

Ethics approval Parental consent has been obtained for all participants under the age of 16 years. The study was approved by the Leeds NHS Research Ethics Committee (IRAS 281544).

Provenance and peer review Not commissioned; externally peer reviewed.

Data availability statement Data are available on reasonable request. Research data may be made available on reasonable request, wherever legally and ethically possible.

Supplemental material This content has been supplied by the author(s). It has not been vetted by BMJ Publishing Group Limited (BMJ) and may not have been peer-reviewed. Any opinions or recommendations discussed are solely those of the author(s) and are not endorsed by BMJ. BMJ disclaims all liability and responsibility arising from any reliance placed on the content. Where the content includes any translated material, BMJ does not warrant the accuracy and reliability of the translations (including but not limited to local regulations, clinical guidelines, terminology, drug names and drug dosages), and is not responsible for any error and/or omissions arising from translation and adaptation or otherwise.

Open access This is an open access article distributed in accordance with the Creative Commons Attribution Non Commercial (CC BY-NC 4.0) license, which permits others to distribute, remix, adapt, build upon this work non-commercially, and license their derivative works on different terms, provided the original work is properly cited, appropriate credit is given, any changes made indicated, and the use is non-commercial. See: http://creativecommons.org/licenses/by-nc/4.0/.

ORCID iDs

Ravin Patel http://orcid.org/0000-0001-7257-1716

Saul N Faust http://orcid.org/0000-0003-3410-7642

\section{REFERENCES}

1 WHO. Available: https://covid19.who.int/region/euro/country/gb [Accessed Aug 2020].

2 Assaker R, Colas A-E, Julien-Marsollier F, et al. Presenting symptoms of COVID-19 in children: a meta-analysis of published studies. $\mathrm{Br} \mathrm{J}$ Anaesth 2020;125:e330-2.

3 Wu Z, McGoogan JM. Characteristics of and important lessons from the coronavirus disease 2019 (COVID-19) outbreak in China: summary of a report of 72314 cases from the Chinese center for disease control and prevention. JAMA 2020;323:1239-42.

4 Ladhani SN, Amin-Chowdhury Z, Amirthalingam G, et al. Prioritising paediatric surveillance during the COVID-19 pandemic. Arch Dis Child 2020;105:613-5.

5 COVID-19: guidance on shielding and protecting people defined on medical grounds as extremely vulnerable. Available: https://www.gov. uk/government/publications/guidance-on-shielding-and-protectingextremely-vulnerable-persons-from-covid-19/covid-19-guidance-foryoung-people-on-shielding-and-protecting-people-most-likely-tobecome-unwell-if-they-catch-coronavirus [Accessed Jul 2020].

6 COVID-19 rapid guideline: children and young people who are immunocompromised. NICE guideline [NG174], 2020. Available: https://www.nice.org.uk/guidance/ng174 [Accessed Jul 2020].

7 Influenza. Available: https://assets.publishing.service.gov.uk/ government/uploads/system/uploads/attachment_data/file/931139/ Green_book_chapter_19_influenza_V7_OCT_2020.pdf [Accessed Dec 2020].

8 ISARIC. Available: https://isaric.tghn.org/COVID-19-CRF/ [Accessed Jul 2020].

9 Mehta NS, Mytton OT, Mullins EWS. SARS-CoV-2 (COVID-19): what do we know about children? A systematic review. Clin Infect Dis 2020.

10 Vicent MG, Martinez AP, Trabazo Del Castillo M, et al. COVID-19 in pediatric hematopoietic stem cell transplantation: the experience of Spanish group of transplant (GETMON/GETH). Pediatr Blood Cancer 2020;67:e28514.

11 Swann OV, Holden KA, Turtle L, et al. Clinical characteristics of children and young people admitted to hospital with covid-19 in United Kingdom: prospective multicentre observational cohort study. BMJ 2020;370:m3249.

12 Ferrari A, Zecca M, Rizzari C, et al. Children with cancer in the time of COVID-19: an 8-week report from the six pediatric onco- 
hematology centers in Lombardia, Italy. Pediatr Blood Cancer 2020;67:e28410.

13 Millen GC, Arnold R, Cazier J-B, et al. Severity of COVID-19 in children with cancer: report from the United Kingdom paediatric coronavirus cancer monitoring project. $\mathrm{Br} \mathrm{J}$ Cancer 2021;124:754-9.

14 D'Antiga L. Coronaviruses and immunosuppressed patients: the facts during the third epidemic. Liver Transp/ 2020;26:832-4.

15 Turner D, Huang Y, Martín-de-Carpi J, et al. Corona virus disease 2019 and paediatric inflammatory bowel diseases: global experience and provisional guidance (March 2020) from the paediatric IBD Porto group of European Society of paediatric gastroenterology, hepatology, and nutrition. J Pediatr Gastroenterol Nutr 2020;70:727-33.

16 Plumb L, Benoy-Deeney F, Casula A, et al. COVID-19 in children with chronic kidney disease: findings from the UK renal registry. Arch Dis Child 2021;106:e16.

17 Fung M, Babik JM. COVID-19 in immunocompromised hosts: what we know so far. Clin Infect Dis 2020.

18 Williamson EJ, Walker AJ, Bhaskaran $\mathrm{K}$, et al. Factors associated with COVID-19-related death using OpenSAFELY. Nature 2020;584:430-6.

19 Docherty AB, Harrison EM, Green CA, et al. Features of 20133 UK patients in hospital with covid-19 using the ISARIC WHO Clinical
Characterisation Protocol: prospective observational cohort study. BMJ 2020;369:m1985.

20 Chan $\mathrm{KH}$, Lee P-W, Chan $\mathrm{CY}$, et al. Monitoring respiratory infections in covid-19 epidemics. BMJ 2020;369:m1628.

21 Issitt R, Booth J, Bryant W. Coronavirus (COVID-19) infection in children at a specialist centre: outcome and implications of underlying high-risk comorbidities in a paediatric population. medRxiv2020.

22 Isba R, Edge R, Jenner R, et al. Where have all the children gone? Decreases in paediatric emergency department attendances at the start of the COVID-19 pandemic of 2020. Arch Dis Child 2020;105:704.1-704.

23 Lynn RM, Avis JL, Lenton S, et al. Delayed access to care and late presentations in children during the COVID-19 pandemic: a snapshot survey of 4075 paediatricians in the UK and ireland. Arch Dis Child 2021;106:e8.

24 Roland D, Harwood R, Bishop N, et al. Children's emergency presentations during the COVID-19 pandemic. Lancet Child Adolesc Health 2020;4:e32-3.

25 Office for National Statistics. Coronavirus (COVID-19) infection survey pilot. Available: https://www.ons.gov.uk/peoplepopulation andcommunity/healthandsocialcare/conditionsanddiseases/bulletins/ coronaviruscovid19infectionsurveypilot/latest\#incidence-rate [Accessed Jul 2020]. 